\title{
COMMENT
}

\section{The mental health of politicians}

\author{
Ashley Weinberg ${ }^{1}$
}

\begin{abstract}
This article considers why mental health is important in our workplaces, including elected political positions on which the effective functioning of our democracy depends. It looks at the job of the politician and its particular challenges, and argues there is a need to ensure that working conditions for all occupations are positive, and why we need to include our elected representatives. The potential consequences for the effective functioning of democracy are also explored and reflections given on where we should we go from here. A recent UK government mantra "No health without mental health" means that some politicians are starting to recognize the value of our psychological well-being as much as that of our physical health-although we might argue this still is nowhere near enough. There seems a long way to go before the reality-and the funding-matches our hopes. Sure enough we all take responsibility for our well-being, but the psychological impact of our working and social environments is well known and governments ignoring this important aspect of our health and functioning in their policies on health and work risk compromising their nation's competitiveness. Perhaps it does not help that as citizens we can be sceptical of the role of our politicians in making important decisions that shape the world in which we live, yet if we turn away from scrutinizing their behaviour we risk compounding the issue and compromising our own well-being too.
\end{abstract}

\footnotetext{
${ }^{1}$ University of Salford, Salford, UK
} 


\section{Introduction}

recent government mantra "No health without mental health" means that some politicians are finally starting to recognize the value of our psychological well-being as much as that of our physical health-although we might argue this still is nowhere near enough! There seems a long way to go before the reality-and the funding-matches our hopes. Sure enough we all take responsibility for our well-being, but the psychological impact of our working and social environments is well known (Siegrist and Marmot, 2004) and governments ignoring this important aspect of our health and functioning in their policies on health and work risk compromising their nation's competitiveness. Perhaps it does not help that as citizens we are often sceptical of the role of our politicians in making important decisions that shape the world in which we live (Flinders, 2012), yet if we turn away from scrutinizing their behaviour we risk compounding the issue and compromising our own well-being for two important reasons.

First, we are all politicians. As humans we are keen to shape our own physical and social surroundings and our survival thus far has depended on the capacity to be political. As politics is about power, it means control is the thing we try to exert over our worlds-however large or small-to have a say over our daily lives and those for whom we care. This makes sense to us, but perhaps it is also something we prefer not to dwell upon as we are told the drive for survival is underpinned by a certain degree of selfishness and need for discretion (Pinker, 2011). To maintain social acceptability, we find words other than "power" and "politics" to describe what we do and instead refer to terms like "autonomy" and "relationships". This does not alter our underlying motivation, but in quietly reflecting on what we seek in life, it is useful to call it as it is. This is important for our own mental health, not least because well-being depends on being able to exercise a level of control over our lives (Warr, 1987; Van Horn et al., 2004). For most of us, this is consumed by the needs of daily living, but can also be reflected in our behaviours as citizens by expressing our views, communicating these to power-holders, voting and protesting and perhaps deciding to run for election to represent others.

Second, the behaviour of politicians carries a clear significance for us all, which becomes immediately apparent when those with considerable power exercise it in a misguided or harmful manner, taking risks and decisions that place others in jeopardy. In thisand in more mundane matters-the well-being of politicians is important. We assume that leaders, for example, are wellfurnished with capabilities, experience and support systems to carry out their role and to cope with the inevitable pressures their responsibilities bring. However, all politicians are human. The temptation to distance those about whom we are sceptical from our own psychological mechanisms risks lulling us into a false sense of security. The mental health of politicians has received some scrutiny, albeit usually limited to historical case studies or analyses "at a distance" (see Freeman, 1991). Some of this is due to their own reticence to disclose such matters, but where empirical research with politicians has been possible, it has shown they are just as likely as other occupations to report symptoms of stress and to react negatively to events beyond their own control by showing increased psychological strain (Weinberg, 2015).

This is important to note because it highlights the need for positive well-being to perform our roles-inside and out of work - to the best of our abilities. This does not mean we need to be perfect to function and it is vital to remember we all risk having periods of ill health-whether physical or mental or both. However, it makes sense for us to ensure there is psychological support for those who need it in every occupation and to strive for the best working conditions to prevent things going wrong.
This includes taking steps to have individuals with relevant and appropriate skill sets for the job in hand (for example, Silvester and Dykes, 2007) and making available coaching and training to those in post. The highest levels in democratic systems face a dilemma here as people rightly expect to choose their leaders and electorates reserve the right to vote for change, that is, this could be someone who does not fit the existing political mould. This can work well in the name of progress, but where it does notand ill health is a factor-what systems are in place to help salvage the situation? Political institutions, like other organizations need a safety net, which benefits individual politicians as well as the wider workforce and indeed the nation. It is just as valid a statement for all occupations where errors, mistakes and absence of appropriate job design and support systems increase the risk of harm.

\section{Feeling the strain?}

So can poor health among politicians be such a problem? Do we care enough about them anyway? The answers should appeal to that part of us, which values our own survival. Case studies of leaders throughout history have shown links between leaders' well-being and their decision making. Examples include former US President Kennedy's treatment for Addison's Disease with amphetamines and his subsequent ill-fated decision to invade Cuba (Freeman, 1991) and former UK Prime Minister Eden's ill health and the subsequent Suez Crisis (Owen, 2006). The reasons for their decisions should not be over-simplified but the surrounding psychological and physical health context cannot be dismissed. It is important to emphasize this not about excluding individuals because of health-related issues, rather recognizing that the job carries highly stressful componentswhich can make some job-holders ill-and ensuring appropriate support is available to make it more possible for politicians to cope. Tackling stigma is an important part of this. Former Norwegian Prime Minister Kjell Magne Bondevik provides a positive example of raising the profile of mental health, which had a consequence of progressive change in public policy. His openness about being diagnosed with depression while in office also helped many Norwegians to be more forthcoming about their own mental health problems. Having stepped down from office, his subsequent re-election demonstrated that stigma can be successfully tackled too.

Such high profile examples tend to focus on leaders, but consider the pressures on national politicians among those who are away from the front-line, performing their roles as elected responsibilities. A debate in the UK House of Commons on mental health in 2012 provided a platform for some politicians to talk about their own experiences, including their reticence to talk about them at all. There was considerable fear of stigma (APPG, 2008) and of providing political ammunition to opponents, however, these MPs were publicly acclaimed for their openness. This did not stop one of them being targeted by a colleague with inappropriate comments in the media, yet refreshingly this resulted in a backlash for the critic.

So is there a case for studying such pressures (or stressors as psychologists call them) and the negative outcomes of experiencing these (or strain as referred to here)? The answer lies in measured effects of the job of politician on those performing it. Surveys of UK MPs have shown increases in symptoms of psychological strain (for example, rising anxiety, lowered selfconfidence, difficulties making decisions) among those entering the job for the first time (Weinberg and Cooper, 2003), which one might expect as we adapt to a new and demanding challenge and indeed these appear to drop again as MPs settle into the role. 
However, the physical symptoms of strain (for example, difficulties sleeping, over-eating, unexplained pains) also increase on first entering the job and remain elevated even one year later (Weinberg and Cooper, 2003). Indeed the All-Party Parliamentary Groups on mental health in Parliament and on mindfulness have published reports highlighting and seeking to address concerns raised in connection with the psychological health of politicians and the wider population. It should not be forgotten that while almost one fifth of MPs report personal experience of a mental health problem (APPG, 2008)-which is representative of the general population-there are other groups where these rates are more than doubled by exposure to poor working conditions and major life stressors such as unemployment, family ill health, relationship and financial difficulties.

For those in work who experience more frequent symptoms of strain, how does this impact on their ability to do the job, and to what extent are politicians as an occupational group vulnerable? It is useful to consider what the job of a national politician actually involves and a challenge here arises from the absence of a job description. However, it is commonly accepted that in the case of UK MPs they represent approximately 70,000 electors, they are expected to attend for parliamentary sittings throughout the year, running offices at Westminster and in their constituency, are active members of their political party, constantly available for media comment and are visible within political processes as representatives and advocates for others, carrying responsibilities for particular causes, campaigns and policies. Fundamentally, the role of MP also involves holding the executive body, that is, the government, to account and ensuring that through parliamentary committees, questions and debate due process is followed and (hopefully) the public good is enhanced. Given the importance of seeing constituents-often in local surgeries held weekly while the MPs is also "at home"-it is not surprising that research with UK MPs shows $92 \%$ report working more than 50 hours per week, including $41 \%$ who work more than 70 hours weekly (Weinberg, 2012).

\section{Should the job of politician carry a government health warning?}

Given the busy nature of many jobs, developing a framework for understanding the sources of pressure facing politicians should not make the mistake of showing them to be a "special case", but instead identify the features of their job that are in common with most others, as well as its unique aspects and particular challenges to the psychological functioning and health of jobholders (Flinders et al., 2016). While the job of politician is not one many of us will do, psychologists have identified features of work common to many occupations and these can be applied to national politics. For example, every job contains a level of control (high, medium or low), an opportunity to use some level of skill, the potential for feedback from others (justifiable or otherwise), variety (or lack of it), demands of some sort and of course exposure to relationships (in which we may rejoice or not!)(Oldham and Hackman, 2010). The levels of each of these and other job characteristics are experienced individually but it is anticipated there is an optimum below or above which the pressure can start to tell (Warr, 2013). Politicians' work shares these features and in addition has aspects which are unique, such as continual media exposure and permeable boundaries between the job and home, such that one MP described it as "a way of life". While there are other busy jobs and lives that will similarly impact on time for family and friends, these are unlikely to end in the public deciding your time is up and "firing" you, often on television in the middle of an election night (see Roberts, 2017). Even before reaching this career-ending jolt, MPs have attested to the toll of constant tensions and high workloads resulting in, "broken health, ruined marriages and exhausted irrationality" (Edwina Currie in evidence to Jopling Committee, 1992).

It is hard to measure satisfactorily the decision making of politicians, as we all have our own perspective on what they should do, yet this is a key aspect of their job. A longitudinal study of MPs suggests that their perceptions of less effective decision-making coincide with MPs' increased experiences of strain (Weinberg, 2015). In other words, there is a real chance stress affects the performance of politicians. Experiencing high levels of strain brought on by exposure to negative events at work does have an impact on how well politicians function-and we would probably recognize this in our own working lives as fairly predictable. For example, in the case of MPs, decisions about their working conditions and in particular the scheduling of the parliamentary calendar, involved all elected politicians in a debate and subsequent vote, that is, there was a level of opportunity for control. Evaluation of the impact of these reforms on MPs showed no overall worsening in psychological health, although there was increased strain for those with constituencies farther from Parliament (Weinberg, 2015). In contrast, when it came to the fallout of the expenses scandal, over the coverage of which MPs had no control, rates of poor mental health doubled (Weinberg, 2015). Clearly there were some politicians who had breached protocol and public expectations, but the negative impact of this was widely felt among MPs including those who had not committed misdemeanours. This finding harks back to the need we all feel for a level of control over our lives and that without it there are psychological risks. It is interesting to note that MPs' perceptions of control are actually lower than those held by the general population (Weinberg et al., 1999), but perhaps it is not surprising given politicians often have to respond to events they did not foresee.

\section{Tackling the sources of stress}

One issue this raises is the negative impact of events on the lives of not just the politician(s) concerned, but also the wider electorate and nation they represent. Furthermore, what can be done to help support individuals, which may also aid politicians' families, colleagues and electors? These questions pose significant questions for the effective functioning of our democratic system. If electorates want politicians who can represent them and hold governments to account, then taking steps to make the job not only possible but realistic is vital.

We know that well-being and work performance are clearly linked and that improving these can be achieved via a range of organizational and individual approaches to the job (for example, Weinberg and Cooper, 2012; Nielsen et al., 2017). These can include preventative strategies to help maintain well-being. For example, attention to how parties choose their candidates has shown the benefits of using the expertize of properly designed ability-based selection procedures common in the wider workplace (Silvester and Dykes, 2007). Furthermore, induction procedures for MPs in the UK and New Zealand have shown considerable contrasts in how well elected individuals are prepared (or not) for the mammoth task ahead of them and, therefore, potential for positive change through the ongoing provision of training (Cooper-Thomas and Silvester, 2014). Research into the psychological impact of job features on politicians has highlighted issues at the interface between work and family life and the potential for positive interventions to reshape the timing of the job to help mitigate its continuing demands (Weinberg, 2015). In the UK, this could also include reducing the need for regular travel from constituencies far 
from London by making available secure electronic voting as well as hosting parliamentary debates around the country. The importance of physical security for MPs has been further highlighted by the murder of Jo Cox at her constituency office and the nature of online threats to elected politicians continues to be an issue requiring vigilance and urgent attention. This appears to be a particular issue for women representatives, some of whom have spoken out about the serious effects on their lives (Phillips, 2017).

For individuals, the availability of psychological support for those who need it is important, wherever it occurs inside or out of politics. The introduction of counselling provision for MPs to help them cope in carrying out their job may be controversial in light of public access to such services, but is consistent with the occupational health provision available to other jobholders in many large workplaces. It also serves to raise the profile among key decision-makers of the importance of support for mental well-being more generally, reminding our elected politicians that such provision is vital for all. As former Prime Minister Bondevik predicted, progressive public policy around mental health has followed on from greater awareness and of openness by politicians about their own experiences.

In addition to job-related strategies, there is a wider need to facilitate public understanding of the role of elected politicians. The popular perception of MPs is often sceptical in the absence of information about their work (Flinders, 2012) and taking steps that raise public awareness of the full range of political roles, starting with citizenship education in schools and beyond (Crick, 2002) and parliamentary outreach initiatives, can only help reduce the disconnection perceived by many between electors and electorates. Such moves to increase public understanding of democratic processes have an important psychological role too. Yes, it's the control factor once again. If we feel part of a democracy by knowing about its workings and recognising our potential to be involved then this can facilitate our own sense of purpose. In other words, politics can be about positive power for all. Pattie et al. (2003) reported how "raising people's interest in politics generally makes them more active citizens...[and]when they are asked to participate (especially by those close to them), they are very likely to do so" (P. 466).

\section{Conclusions}

Despite the promising rhetoric, maintaining the funding needed to enhance psychological health of the population faces a range of challenges. Raising the profile of the mental well-being of politicians is important for a number of reasons. First, it is integral to ensuring our elected representatives are best placed to function effectively in their role which has direct consequences for all. Second, it signifies the importance of considering job design-whether in politics or other occupations-for doing the best we can with and by the human potential in our workplaces. Finally, increased recognition of the role of mental health in daily functioning-inside and out of workplaces-carries positive potential for our approach to life in ordinary and extraordinary situations. Failure to do so has the potential to undermine not only the democracy we hold dear but our humanity too.

\section{References}

All-Parliamentary Group on Mental Health (APPG). (2008) Mental Health in Parliament. APPG on Mental Health: London.

Cooper-Thomas H and Silvester J (2014) Ideas and Advice to Accelerate the Transition for New MPs entering New Zealand's House of Representatives [online]. Available from: https://margf2011.files.wordpress.com/2014/09/ report-to-support-new-mp-adjustment-final.pdf.

Crick B (2002) Education for citizenship: The citizenship order. Parliamentary Affairs; 55 (3): 488-504.
Currie E (1992) Jopling Committee Report Report from the Select Committee on Sittings of the House. Vol. 1. HMSO: London.

Flinders M (2012) The demonisation of politicians: Moral panics, folk devils and MPs' expenses. Contemporary Politics; 18 (1): 1-17.

Flinders M, Weinberg A and Geddes M (2016) The Health of Democracy Recast: The Politics of Mental Health and the Mental Health of Politicians. Paper presented at the BPS Annual Conference, Nottingham. Proceedings of the BPS, Vol. 24, no. 2.

Freeman H (1991) The human brain and political behaviour. British Journal of Psychiatry; 159 (1): 19-32.

Nielsen K, Nielsen MB, Ogbannoya C and Isakson K (2017) Workplace resources to improve both employee well-being and performance: A systematic review and meta-analysis. Work and Stress; 31 (11): 1-20.

Oldham GR and Hackman JR (2010) Not what it was and not what it will be: The future of job design research. Journal of Organizational Behavior; 31 (2-3): 463-479.

Owen D (2006) The effect of Prime Minister Anthony Eden's illness on his decision-making during the Suez crisis. QJM: An International Journal of Medicine; 98 (6): 387-402.

Pattie C, Seyd P and Whiteley P (2003) Citizenship and civic engagement: Attitudes and behaviour in Britain. Political Studies; 51, 443-468.

Phillips J (2017) Everywoman: One's Woman's Truth About Speaking the Truth. Penguin: London.

Pinker S (2011) Decline of violence: Taming the devil within us. Nature; 478 (7369): 309-311.

Roberts J (2017) Losing Political Office. Palgrave Macmillan: London.

Siegrist $J$ and Marmot M (2004) Health inequalities and the psychosocial environment-Two scientific challenges. Social Science \& Medicine; 58 (8): 1463-1473.

Silvester J and Dykes C (2007) Selecting political candidates: A longitudinal study of assessment centre performance and political success in the 2005 UK general election. Journal of Occupational and Organisational Psychology; 80 (1): $11-25$.

Van Horn JE, Taris TW, Schaufeli WB and Schreurs PJG (2004) The structure of occupational well-being: A study among Dutch teachers. Journal of Occupational and Organizational Psychology; 77 (3): 365-375.

Warr PB (2013) Jobs and job-holders: Two sources of happiness and unhappiness. In: David SA, Boniwell I and Conley Ayers A (eds). The Oxford Handbook of Happiness. Oxford University Press: Oxford, pp 733-750.

Warr PB (1987) Work, Unemployment and Mental Health. Oxford University Press: Oxford.

Weinberg A (2015) A longitudinal study of the impact of changes in the job and the expenses scandal on UK national politicians' experiences of work, stress and the home-work interface. Parliamentary Affairs; 68 (2): 248-271.

Weinberg A (ed) (2012) Should the job of national politician carry a government health warning?-The impact of psychological strain on politicians. In: The Psychology of Politicians. Cambridge University Press: Cambridge, pp 123-142.

Weinberg A and Cooper C (2003) Stress among national politicians elected to parliament for the first time. Stress and Health; 19 (2): 111-117.

Weinberg A and Cooper C (2012) Stress in Turbulent Times. Palgrave Macmillan: Basingstoke.

Weinberg A, Cooper C and Weinberg A (1999) Workload, stress and family life in British members of parliament and the psychological impact of reforms to their working hours. Stress Medicine; 15 (2): 79-87.

\section{Additional information}

Competing interests: The author declares that there are no competing financial interests.

Reprints and permission information is available at http://www.palgrave-journals.com/ pal/authors/rights_and_permissions.html

How to cite this article: Weinberg A (2017) The mental health of politicians. Palgrave Communications. 3:17081 doi: 10.1057/palcomms.2017.81.

Publisher's note: Springer Nature remains neutral with regard to jurisdictional claims in published maps and institutional affiliations.

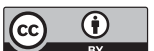

This work is licensed under a Creative Commons Attribution 4.0 International License. The images or other third party material in this article are included in the article's Creative Commons license, unless indicated otherwise in the credit line; if the material is not included under the Creative Commons license, users will need to obtain permission from the license holder to reproduce the material. To view a copy of this license, visit http://creativecommons.org/licenses/by/4.0/

C The Author(s) 2017 